\title{
An Institutional Approach To Operations Management In Internet Based Production Concepts
}

Thorsten Blecker (blecker@ieee.org), University of Klagenfurt, Austria

\begin{abstract}
An important change in the socio-economic environment of industrial firms is the increasing diffusion of Internet Technologies in production processes. Applications of Internet Technologies may be directly implemented on the shop floor, e.g. in networking dislocated assembly lines, as well as in assisting management processes, e.g. in production planning and control. This leads to a strong approximation of the traditional production and operation systems and the Internet Technologies. While traditional production concepts, such as Lean Production, World Class Manufacturing and Agile Manufacturing, inevitably disregard this development, new production concepts arise that fundamentally consider the application of Internet Technologies on the shop floor. However, from a business management perspective, industrial firms have to accomplish new operating requirements deriving from this technological change. This paper provides a discussion of the consequences of Internet Technologies on operations management, as well as of production concepts based on Internet Technologies from an institutional point of view.
\end{abstract}

\section{Introduction}

Currently we have to realize a major change in the technological basis of manufacturing or even all production processes. The diffusion of new information and communication technologies, especially Internet Technologies, on the shop floor increases and enables an accelerated evolution of decentralized concepts, e.g. in Production Planning and Control (PPC). It seems as if Internet Technologies may reach into the automation and control level of every assembly line, as well as interconnect business and technological levels of the firm in the sense of vertical integration.

Both, formal and empirical studies have verified a significant increase in productivity of manufacturing processes by intraorganizational applications of modern information and communication technologies (Barua/Lee 2001, pp. 37). Therefore, this change has a high influence on operations management. While traditional Production Concepts such as Lean Production, World Class Manufacturing and Agile Manufacturing inevitably disregard this development, new Production Concepts arise that fundamentally consider the application of Internet Technologies on the shop floor. However, these concepts focus on the implementation of Internet Technologies in the production system and induce thereby massive consequences in the information and coordination processes, which will be analyzed in new institutional economics.

\section{Advances in Internet Technologies and Internet based Production Concepts}

Usually we understand the term Internet Technologies in the context of the well-known Internet as the technological basis of global information and a communication network. However, the term "Internet Technologies" does not prejudge an external relevance. The term Internet Technologies describes a family of technologies suitable for exchanging structured data about package-oriented transmissions on heterogeneous platforms, in particular protocols, programming languages, hardware, and software. Yet, the internal application of these technologies focuses on Intranets for office information systems. In the future, the main industrial application area for Internet 
Technologies is in Field Area Networks (FAN). This means the interconnection, as well as networking of automation infrastructure and machine controls on the shop floor (Blecker/Haber 2001, pp. 338).

Yet, fieldbuses as a traditional, but competing network technology are still dominating in production processes, e.g. the ProfiBus concept of Siemens. In the future, Internet based FAN will complement or even replace fieldbuses. Since 1985, industrial firms have utilized Ethernet on the shop floor. Due to new standards, Industrial Ethernet reduces the technological limits that have existed up to now to the applicability of Internet based FAN or even the replacement of fieldbuses. Industrial Ethernet is based on the relevant international standards (e.g. IEEE 802.3). It is adjusted to the specific environmental conditions, for example regarding electromagnetic compatibility, shaking, moisture, and chemical resistance (Siemens 1999, pp. 20). In some sectors Ethernet and Industrial Ethernet are already the de facto standards, e.g. in the automotive industry, process industry and in plant engineering.

The technological improvement of Industrial Ethernet and/or Internet Technologies in general does not necessarily enable a total replacement of fieldbuses. On the one hand, some applications or existing machinery still need FAN based on fieldbuses. On the other hand, fieldbuses such as ProfiBus evolve towards a convergent, interconnective infrastructure, e.g. as in ProfiNet. Hence, even where Ethernet cannot replace fieldbuses, Internet Technologies connect the different assembly lines together and transfer detailed data from the shop floor to the office et vice versa. Consequently, a comprehensive application of Internet based FAN enables the expansion of existing Intranets in office automation to all production processes, especially manufacturing. Enabling technologies, such as Web Services, Active Technologies, and Industrial Frameworks (based on .NET or Sun ONE), will support intelligent manufacturing technologies and a homogeneous network from office to manufacturing. These platforms have an enormous potential to reduce (transaction) costs within the production system (Blecker 2003a, pp. 39). Therefore, Internet Technologies become an ubiquitous network respectively an omni-present information infrastructure in the complete industrial firm.

In sum, Internet based Field Area Networks (FAN) may connect office information systems with the automation and control level of every assembly line. It is not surprising that applications of Internet Technologies in production processes increase and that many automation technology suppliers combine Internet Technologies with their products. This leads to a convergence of the traditional production systems and Internet Technologies (Blecker 2001, pp. 19). It explicates the unification of technologies with different features to a homogeneous service bundle, which enables the revision of traditional Production Concepts or even the development of new Production Concepts.

The considerable advantages of Internet Technologies are noncontroversial for the technological infrastructure of communications and information in production processes. According to Atherton's (1999) idea Java-based applications should support planning and control of all production processes. In this scenario Internet Technologies integrate the technical CAx-Systems with the economical Enterprise Resource Planning (ERP). This means that Java connects different technological environments and acts as a gateway between automation technology and information technology. This scenario reminds one of the already known basic idea of Computer Integrated Manufacturing (CIM). The application of Internet Technologies is set into the center of the considerably extensive and heterogeneous functionalities that are integrated in a homogeneous web-interface. Nevertheless, this attempt does not achieve new advantages vis-à-vis the CIM-concept and not quite a new Production Concept. It only centers the attention towards industrial applications of Internet Technologies. However, in the literature some selfcontained Production Concepts exist, which more or less consider Internet Technologies in production processes. We define Production Concepts as an (in theory) well-founded guiding-idea, based on empirical knowledge where appropriate, on the organization, planning, control and evolution of production systems with the main objective to enhance the competitiveness of the firm (Blecker 2003a, pp. 12). It consists of the definition of an optimal state of the technological and economic elements of the production system, as well as their relationships to each other in their practical (application-near) recommendations for achieving the aimed state, as well as a description of required methods and instruments for their realization. Therefore, we discuss the different approaches to Internet based Production Concepts following these four criteria: 1. the guiding idea presented in the literature, 2. the aimed conditions of the production system, 3. (general) recommendations for achieving the aimed conditions and finally 4. the discussed instruments. 
E-Manufacturing or Electronic Manufacturing are keywords, which have been discussed recently in connection with terms like E-Commerce and E-Business. The main guiding ideas of E-Manufacturing are the control of the entire value chain with E-Technologies as a central task of industrial firms and a comprehensive optimization of the supply chain (Wildemann 2000, pp. 22). For realizing these ideas, E-Manufacturing aims the continuous alignment of manufacturing at the individual customer requests, high quality of products and low costs. E-Procurement, cooperative manufacturing operations in production networks, flexible and decentralized planningand control systems, as well as a direct networking of decentralized production units are seen as a general framework in which industrial firms have to operate. Therefore, sophisticated build-to-order concepts, the integration of customers and suppliers, as well as the application of E-Technologies are recommended. Additionally, an integration of dislocated information systems is required. E-Manufacturing fills the different demands through the application of instruments such as Internet based PPC, a product data management/engineering data management (PDM/EDM), as well as newer CAx-Technologies. However, this is in our understanding not a new manufacturing concept, but only a relatively non-structured collection of approaches and technologies that focus on the application of so-called E-Technologies. It outlines only qualities of manufacturing in E-Commerce.

The Information-Based Manufacturing shows a higher reference to production processes. This approach describes as a guiding idea a highly information-dependent production, which is distributed throughout several enterprises. As aimed conditions, it refers a strong customer relationship, a high velocity of (re)actions, networking of decentralized production processes and synchronized demands (Shaw 2001, pp. 8). Similar to E-Manufacturing the Information-Based Manufacturing recommends build-to-order concepts, supply chain coordination and optimal information sharing. Therefore, exemplary instruments are an optimal synchronization of production factor appropriation and scheduling between the firm and their partners in the entire supply chain. Companies must have agent systems, decentralized planning and operation systems, as well as integrated information and automation technologies in the dislocated production processes for the realization of Information-Based Manufacturing (e.g. Veeramani/Wang 2001, pp. 246). Thus, the commitment of Internet Technologies does not occur in an intraorganizational way, but mainly interorganizationally, for example based on WebEDI, or during communication with the customers. The focus of the analysis differs obviously from our intraorganizational perspective.

Beavers' examines manufacturing and the different production processes within his concept of the $e$ Factory and considers the necessary qualities of industrial firms. He formulates as a guiding idea for the e-Factory, that it is an upright element of an electronic supply chain in E-Business and defines this approach as "a new, allencompassing term for all of the electronic control, automation, and intelligent machines that occupy today's factory environment" (Beavers 2001, p. 14). The main goals are a quickly reacting production system respectively low operation times, a high process orientation, as well as the integration of one's own enterprise into the supply chain. Therefore, in addition to the application of E-Technologies, Beavers recommends a cooperative production process in the network structures of a supply chain (Enterprise Extension) and a strong coordination between outsourcing and inhousing. Discussed instruments are electronic control systems for all automation technologies and an extensive application of information systems, e.g. ERP, Warehouse Management and PDM/EDM. We share the fundamental opinion that modern information and communication technologies penetrate the production processes and pass the production up to the automation level, as well as to the machine control. However, we criticize the delimitation of the e-Factory on electronic supply chains and/or the E-Business. On the one hand, we absolutely see a high application potential of Internet Technologies within industrial firms, which were not subjects of the EBusiness up to now and would traverse a material production in the classical sense. On the other hand, we criticize Beavers' perspective, which is at least partially enterprise-external. However, it is more serious that Beavers writes generally about "electronic control“, without a specification, e.g. on Internet Technologies. Therefore, the definition encloses almost all modern control mechanisms in manufacturing. Even NC, CNC or DNC machinery contains an electronic excitation and/or control. Thus, the definition is not selective enough and does not provide a suitable explanation of an Internet based Production Concept.

Positive approaches forthe application of Internet Technologies in manufacturing are observable in context with the keyword 'Web-Integrated Manufacturing' in engineering research. Web-Integrated Manufacturing describes the general application of Internet Technologies in manufacturing, for example, agent based systems, Java, Jini and SOAP (e.g. Kuehnle/Klostermeyer/Lorentz 2001, pp. 463). Even the international research project "plant 
automation based on distributed systems" (http://www.pabadis.org/) uses this approach as a theoretical basis. The project goal is the application of decentralized, distributed systems of office communication within the machine control on the shop floor in order to survive within turbulent environments. This is supposed to lead to certain aimed conditions, namely highly flexible, adaptive and simply reconfigurable production systems. Reconfigurable production systems combine the respective advantages of high-productive and high-flexible systems, because they may be adapted immediately regarding their structure, functionality, and capacity, as well as their inherent technology to changed demands. For the realization of this scenario, this approach recommends distributed computing and distributed problem solving in automation on the shop floor. Therefore, the instruments of Web-Integrated Manufacturing focuses on a decentralized agent system in manufacturing and embedded systems in automation technologies. Furthermore, these agent systems have to substitute occasionally existing Manufacturing Execution Systems (MES). However, up to now, the different projects analyze the Internet Technologies only as a basis of the Web-Integrated Manufacturing and examine their applications in technical systems. A definition of a Production Concept occurs just as little as a strategic substantiation.

Additionally, Huang/Mak use the term Web-Integrated Manufacturing during the preparation of a special edition of the International Journal of Computer Integrated Manufacturing. Both Huang/Mak (2001a, pp. 3; 2001b, pp. 125) as also the other contributors to this journal only describe individual, dislocated applications based on Internet Technologies for the product design and manufacturing. Therefore, the main idea of this approach is the application of interorganizational CAx-technologies, especially CAD/CAM systems, e.g. for the distributed product design (Chang/Pan/Harrison 2001, pp. 14). The aimed condition of Web-Integrated Manufacturing is a flexible, distributed production process between two ore more collaborates. Hence, the recommendations for realizing WebIntegrated Manufacturing are the development of interorganizational information systems for a dislocated product development, rapid prototyping, the application of automated production systems based on so-called Web-Applications. The authors discuss mainly CAx and CAD/CAM, quality function deployment and the integration of the dislocated intra- and interorganizational information systems in the sense of EAI as instruments. While Huang/Mak does not systematize the term Web-Integrated Manufacturing exactly, they define the term 'Web Application' as the essential element of Web-Integrated Manufacturing (Huang/Mak 2001a, p. 4; 2003, pp. 56). However, with this definition Web-Integrated Manufacturing is considered merely very general as the application of Internet based technologies in the production and does not lead to any Production Concept.

Figure 1 shows a comparison between the different approaches related to Internet based Production Concepts following the discussed criteria. We can diagnose that both scientific research and industrial practice impose the importance of the Internet Technologies for manufacturing. Nevertheless, we criticize that the individual island solutions, as well as the first more comprehensive concepts concentrate primarily on technical aspects.

A more comprehensive concept of Internet Technologies applications in production processes has to focus a more consistent and continuous commitment of Internet Technologies in industrial firms and has to deal with the current evolutions of the production technique, as well as operations management. Mainly we expect that such a concept focuses not only on the dislocated usage of the Internet Technologies as a communication media between a company and their partners, suppliers, and customers. Instead, it has to concentrate itself on the consequences of Internet Technologies for the shop floor, new options of Internet Technologies in operations management and their effects on the strategic and operative management of industrial firms. Such a concept is Web-based Manufacturing (Blecker 2003a; 2003c). It is based on the continuous and global application of multimedia Internet Technologies in the technical and managerial processes concerning industrial production and reaches from the office into the automation level. Hence, Web-based Manufacturing is a technology driven Production Concept, significantly based on the Internet Technologies. However, this does not mean that it is inevitably technology centered. Instead, this concept focuses on a rigorous perspective from business administration, as well as operations management and concentrates on the up to now unused potentials of the Internet Technologies in production processes. Thus, we define: Web-based Manufacturing is an Internet Technology based Production Concept that is an (in theory) wellfounded guiding-idea, based on empirical knowledge where appropriate, on the organization, planning, control and evolution of production systems. It aims at easily reconfigurable, high flexible production systems based on the comprehensive application of Internet Technologies on the shop floor. Due to the actual developments in market structures and current competitive strategies the main goal of Web-based Manufacturing is to achieve market- and 
resource oriented competitive advantages supported by the application of Internet Technology based technological and/or conceptual procedures and processes in a decentralized coordinated, according to informational criteria organized and ad-hoc structures forming production environment. Because of the coverage of the whole production, this concept should have been denoted in a strictly speaking sense as "Web-based Production". However, we use the term Web-based Manufacturing due to the below discussed uncertainty concerning the definitions of the terms production and manufacturing and analog to the widely used term Computer Integrated Manufacturing, which covers more than manufacturing as well.

Figure 1: Comparision between different Production Concepts based on Internet Technologies

\begin{tabular}{|c|c|c|c|c|c|}
\hline Criteria & $\begin{array}{c}\text { E-Production / } \\
\text { E-Manufacturing }\end{array}$ & $\begin{array}{c}\text { Information- } \\
\text { Based Manufacturing }\end{array}$ & e-Factory & $\begin{array}{c}\text { WIM } \\
\text { (IFF / PABADIS) }\end{array}$ & $\begin{array}{c}\text { WIM } \\
\text { (IJCIM) }\end{array}$ \\
\hline Guiding Idea & $\begin{array}{l}\cdot \text { production in } \\
\text { e-commerce } \\
\text { optimization of the } \\
\text { Supply Chain }\end{array}$ & $\begin{array}{l}\text { - integration in Supply } \\
\text { Chain Networks } \\
\text { - distributed, information- } \\
\text { dependent production }\end{array}$ & $\begin{array}{l}\text { production as } \\
\text { vertical element } \\
\text { of the Supply Chain } \\
\text { in e-business }\end{array}$ & $\begin{array}{l}\text { - decentralized, agent- } \\
\text { based automation } \\
\text { as technical reply to } \\
\text { turbulent environments }\end{array}$ & $\begin{array}{l}- \text { interorganizational } \\
\text { CAD/CAM combined } \\
\text { with Internet } \\
\text { Technologies }\end{array}$ \\
\hline $\begin{array}{l}\text { Aimed } \\
\text { Conditions }\end{array}$ & $\begin{array}{l}\cdot \text { customer focus } \\
\cdot \text { high quality } \\
\text { - low costs }\end{array}$ & $\begin{array}{l}\cdot \text { customer focus } \\
\text { - high velocity of } \\
\text { (re)actions } \\
\text { - networked production } \\
\text { - synchronized demands }\end{array}$ & $\begin{array}{l}\text { - process orientation } \\
\text { - low operation time } \\
\text { - production in an } \\
\text { e-Supply Chain }\end{array}$ & $\begin{array}{l}\cdot \text { high flexibility } \\
\cdot \text { adaptive } \\
\cdot \text { reconfigurable } \\
\text { subsystems }\end{array}$ & $\begin{array}{l}\text { - flexible } \\
\text { - interoperable }\end{array}$ \\
\hline $\begin{array}{l}\text { Recommen- } \\
\text { dations }\end{array}$ & $\begin{array}{l}\cdot \text { build-to-order } \\
\cdot \text { e-technologies } \\
\cdot \text { integration of } \\
\text { customer \& } \\
\text { suppliers }\end{array}$ & $\begin{array}{l}\text { - } \text { build-to-order } \\
\text { - Supply Chain } \\
\text { coordination } \\
\text { - information sharing }\end{array}$ & $\begin{array}{l}- \text { enterprise extension } \\
- \text { outsourcing } \\
- \text { inhousing } \\
\text { - cooperative manu- } \\
\text { facturing operations }\end{array}$ & $\begin{array}{l}\cdot \text { distributed } \\
\text { computing } \\
\cdot \text { distributed } \\
\text { automation }\end{array}$ & $\begin{array}{l}\text { - high automation } \\
\text { - dislocated product } \\
\text { development } \\
\text { - development of } \\
\text { web-applications }\end{array}$ \\
\hline Instruments & $\begin{array}{l}\cdot \text { e-procurement } \\
\cdot \text { decentralized CAx } \\
\cdot \text { decentralized } \\
\text { production planning } \\
\cdot \text { PDM/EDM }\end{array}$ & $\begin{array}{l}\cdot \text { web-EDI } \\
\cdot \text { agent systems } \\
\text { - decentralized } \\
\text { production planning } \\
\cdot \text { Integration of IT and } \\
\text { automation }\end{array}$ & $\begin{array}{l}\cdot \text { electronic machine } \\
\text { control } \\
\text { - business information } \\
\text { systems, e.g. ERP, } \\
\text { CRM, SCP } \\
\text { - (e-)procurement }\end{array}$ & $\begin{array}{l}\cdot \text { agent systems } \\
\cdot \text { embedded systems } \\
\text { - mobile code } \\
\text { - reduction of MES- } \\
\text { System }\end{array}$ & $\begin{array}{l}- \text { CAx or CAD/CAM } \\
\text { - quality function } \\
\text { deployment } \\
\text { - enterprise appli- } \\
\text { cation integration }\end{array}$ \\
\hline
\end{tabular}

Source: Blecker (2003b)

Web-based Manufacturing is still work-in-progress (Blecker 2003b; 2003c; Blecker/Graf 2003). Nevertheless, we can consider that the application of an Internet based production concept may lead to the achievement of new, up to now practically unrealizable approaches and structures of production processes. By now, it is impossible to predict completely the potential benefits of these modifications. However, due to the massive integration of Internet Technologies into manufacturing in the future, some authors point out the necessity of elementary modifications in management thinking, especially in industrial firms (Blecker 2003a; see crucially for this purpose Neumann 2002, p. 26).

\section{New Institutional Economics as Approach to Operations Management}

On the one hand, the analysis of the changes in operations management has to include the modification of the production systems as a subsystem of the enterprise. Modifications in the production system induce adjustments in operations management, because either operations management has to react to the modifications by forming an intervention or the initial motivation for already selected and carried out management procedures changes. On the other hand, we need an economic theory as a basis of the analysis since we have to examine the behavior of the different actors in the production system and the arising consequences from the viewpoint of Business Administration respectively operations management. Furthermore, we have to mention that just the application of modern information and communication technologies, such as Internet Technologies, influences the optimal distribution of tasks between the elements of the production system, as well as their coordination and cooperation for manufacturing operations. This is particularly important in systems with incomplete and/or asymmetric 
information, since the arising transaction costs are an economically important factor. For example, North (1991, pp. 97) refers to studies identifying that transaction costs represent $45 \%$ of the added value in the USA. Since these studies, they only consider marketable transactions with quantifiable costs and do not analyze coordination and management activities in production processes, Fels (1992, p. 1047) assumes, that the institutionally fixed transaction costs are economically more important as the usually examined production costs. Consequently, we need a theory that investigates the organization and coordination processes in the internal structure of an enterprise, as well as the resulting cost and efficiency effects.

Therefore, we will use the different theories of the new institutional economics as an approach for our examination. While the neoclassical microeconomics only considers organizations as monolithic units, the new institutional economics are established approaches of the organizational research (see papers in Furubotn/Richter 1991). Though the new institutional economics follow microeconomic theory, they (partially) override reality-far premises. The main thesis is that abilities, knowledge and information of the individuals are heterogeneous. From this it follows, that the assumption of a walrasian auctioneer of the neoclassical competition theory (Walras 1874) is not tenable anymore. The walrasian auctioneer should guarantee an economic balance in a system with completely flexible prices and actors acting on the basis of complete information. Instead, acquisition and protection of information are not free. Friction and motivation problems in the interaction processes also arise. New institutional economics based analysis is a solution for the problems occurring in economic systems. Institutions are defined as systems of norms and rules, which act as restricting conditions, affecting the behavior of economic actors. For example, such institutions are (social) conventions and rules, laws, procedures, property rights, and contracts, as well as organizational structures that evolve both evolutionary and because of purposeful managerial actions.

The main goal of new institutional economics is to find statements about the efficient organization of institutional arrangements. This means, economic decisions within and over institutions are examined. The new institutional economics is composed of different methodological-related approaches with identical assumptions about the behavior of economic actors, such as individual utility maximization, bounded rationality and opportunistic behavior. These approaches are mainly: the property rights theory, the principal-agent theory (agency theory) and the theory of transaction costs. These theories allow a reunion of economic, in particular microeconomic approaches, and business administration, exceeding the classical production theory and enclosing the general management as well. Fandel and Lorth (2001, pp. 273), as well as Franck and Jungwirth (2001, pp. 273) show clearly the importance of institution economical analyses in order to solve problems arising in operations management. For example, according to Foss $(1998$, p. 11) it is possible to describe the specialization of actors in a production system regarding the property rights theory as "a subdivision of user rights over assets, so that each individual holds rights over a more narrow set of assets or holds a more narrow set of rights over the same asset". The modularization in production processes may be discussed as a reallocation of property rights in a specific organization (Picot/Schneider 1988, pp. 111; Wigand et al. 1997, p. 180). The eventual appearance of discretionary behavior results from unspecified property rights in the modules (Foss 1998, p. 13), whereas the arising transaction costs are determined by a specific organization, the specifity of the goods, as well as transaction conditions in the production system, namely the information impactedness, the transaction frequency and the transaction atmosphere (Williamson 1975). Optimal organizational structures and optimal transaction conditions may reduce transaction costs and improve the competitiveness of the firm. Furthermore, the agency theory explains optimal leadership and controlling mechanism in decentralized structures (Wigand et al. 1997, pp. 183) even on the shop floor.

However, the different approaches of new institutional economics deal with the behavior and interaction of actors, e.g. whole companies or employees, in economic systems (e.g. Wigand et al. 1997, p. 37). In order to apply new institutional economics to operations management, it is useful to speak about actors referring to autonomous acting units within the production system, which often endue local (computational) intelligence. We differentiate three types of actors in production systems. The first type consists of human actors, e.g. planners and workers. Because of the increasing integration of modern information and communication technologies into automation systems and their growing local "intelligence", artificial actors build up the second type of actors in production systems. For example, facilities with embedded computational intelligence may act autonomously in a production process. Like human actors, they perform different tasks and interact with other actors in the production system under physical and cognitive limitations. The third type of actors consists of composed units. We call this type 
organizational actors, because they consist of a varying number of human and/or artificial actors following organizational principles, e.g. autonomous or virtual teams on the shop floor, and act as a whole. The actors of the production system have a broad set of abilities to build up relationships with other actors. Thus, we can claim, that every actor may interact with every other actor. These interactions can range from simple data transfer to complex coordination processes. Additionally, the interaction of actors is not limited to the production system, which means that they can communicate with actors outside the production system. We assume that qualities and capabilities of each actor change by applying Internet Technologies for their interconnection on the shop floor, as well as by converging different technologies. Additionally, a decisive influence of modifications of the actors' capabilities and/or of their coactions on operations management is conjecturable. The exact content of contracts between the different actors, their organization and interaction generally determine the physical and economic output of the production system. Therefore, only the discussed differentiation between the three types of actors allows the institutional analysis of coordination and communication processes, as well as of consequences for operations management resulting from Internet based Production Concepts.

\section{Operations Management in Internet based Production Concepts from an Institutional Point of View}

Both, management and engineering literature define the terms manufacturing, production and operations (management) very heterogeneously. First, some authors understand manufacturing as an all-encompassing term, which includes production and operations. Rehg/Kraebber $(2001$, p. 2) define manufacturing as "... a collection of interrelated activities that includes product design and documentation, material selection, planning, production, quality assurance, management and marketing of goods". For a second group production is the superordinate concept and manufacturing, as well as operations management only describe subsystems or functions. For example, in this understanding the term operations management includes "...creating, operation and controlling a transformation system that takes inputs of a variety of resources and produces outputs of goods needed by customers" (Naylor 2002, p. 5; see also Black 2000, pp. 423). Thirdly, the term operation and operations strategy are broader than manufacturing or manufacturing strategy so that operations management describes "...the activity of managing the resources and processes that produce and deliver goods and services" (Slack/Lewis 2002, p. 5; see also Waller 1999, p. 1). We partially accompany the third group. In our understanding production describes a function of a (industrial) firm consisting in creating a transformation system and combining internal and external resources by applying technological and conceptual procedures in order to generate goods and services for further possessing and/or as marketable output for serving the customer. Manufacturing is only a specific form of production processes based on mechanical technologies and activities; whereas operations are the necessary activities in production systems to provide services and/or goods in general. Therefore, operations management describes planning, organizing and control of all resources and activities in operating production systems. In comparison to production management operations management does not include the system creation and product design.

Additionally, we have to clarify the term production system. Some authors define production systems as a broad system, covering “....all aspects of business and commerce including manufacturing, sales, advertising, and distribution" (Black 2000, p. 423). Following the above definitions of production, manufacturing and operations, this explanation is excessively extensive. We understand a production system as a subsystem of the enterprise for the transformation of input factors, e.g. goods and services, in output factors, e.g. tangible goods and services for satisfying customer needs. We divide the production system into two basic subsystems: the management subsystem and the operation subsystem. These subsystems are interconnected and interwoven by an information system. The operation subsystem deals with the original transformation processes and includes all facilities, machines, logistical equipment and employees (blue collar workers). The management subsystem is responsible for the short run (operational) design, planning and control of the entire operation subsystem. This differentiation is the basis for the following analysis of the consequences of Internet based Production Concepts. 


\subsection{Operation Subsystem}

From the perspective of the operation subsystem we have to discuss the influences of Internet Technologies and Internet based Production Concepts on the different elements of the operation subsystem and the operations itself. We distinguish between the system elements machines \& facilities, information system, and materials flow system, as well as employees \& work places. Figure 2 illustrates potential modifications and changes of these elements due to Internet based production concepts.

\section{Figure 2: Potential Modifications and Changes of the Elements of the Operation Subsystem Derived from Internet based Production Concepts}
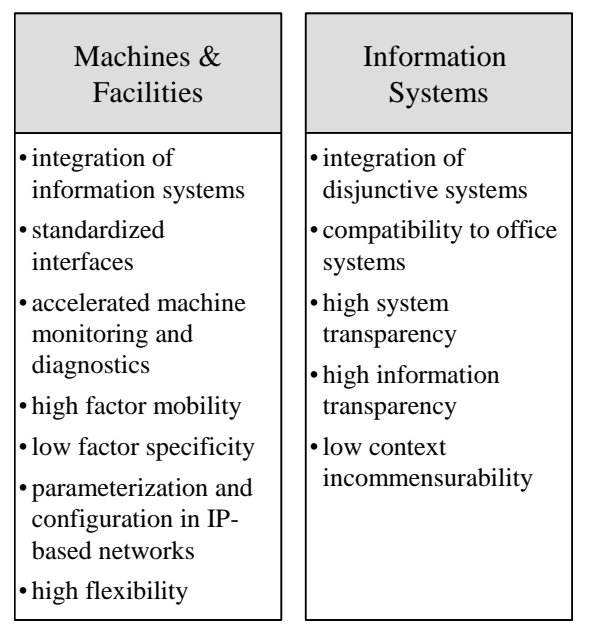

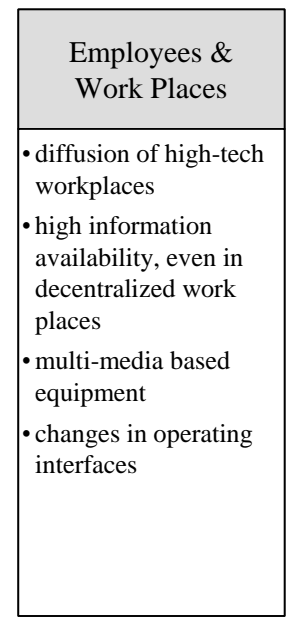

The main idea of all Internet based Production Concepts is increasing the application of Internet technologies in production, especially in interconnecting and networking the different elements of production respectively operation subsystems. This leads to a strong convergence of the traditional production and operation concepts, as well as Internet technologies. Thereby the automation technologies receive their own, local data processing capacity in the sense of a distributed artificial intelligence so that a distributed automation with high flexibility, adaptivity and reconfigurability becomes possible (Pabadis 2001, p. 15). Furthermore, the application of Internet Technologies enables the acceleration of the machine monitoring and diagnostics based on the application of standardized interfaces between specific system elements, homogeneous human machine interfaces in web browsers, the possibility for the measure realization from a single computer and IP based networks for the interconnection and routing of control information (Schueber 2001, p. 11). In sum a parameterization and configuration of automation technologies becomes possible and reduces set-up costs, as well as idle costs. Additionally, the application of the open and highly standardized Internet Technologies reduces the costs of the interconnection of automation technology per se.

Since we argue a convergence of the production and information technologies, we can assume that the qualities of the information system partially determine the quality of the resultant super system. Networking with the aid of an Industrial Twisted Pair, the applications of standardized interfaces based on Industrial Ethernet up to interconnections on the basis of Sub-D or even the RJ45 cables, usually applied in office networks, enormously increase the flexibility and the usability of automation technology (Siemens 1999, pp. 21). Consequently, the specificity, defined as uniqueness or unique usability of facilities and machinery, also decreases. In the ideal case, the movement of facilities and machinery becomes possible, similarly to local area networks in offices, where computers can be connected nearly at any time and at any place. From an economic or even an institutional perspective this means that the factor mobility increases (Schumann 1993, p. 389). 
This leads to the institutional interpretation of the modifications and changes in the operation subsystem. At first, standardized interfaces and/or the reduction of changes in media formats due to a higher integration of the machines and facilities allow a reduction of the searching costs and time for information. This corresponds to the reduction of transaction costs due to the application of information technologies in general, already discussed by several authors in connection with cooperation forms such as virtual enterprises. The fix and variable costs of information processing are reduced and the diffusion of knowledge on the shop floor is accelerated. Consequently, specificity on production processes is reduced and (internal) transactions are standardized. This means, market coordination forms become more useful in opposition to hierarchical coordination forms even in the operation subsystem (Wigand et al. 1997, pp. 181). However, standardized interfaces and the convergence of the production and information systems are useful from the viewpoint of the property-rights theory and the agency theory as well. The mentioned local intelligence in the machines and facilities achieved by Internet Technologies is in fact an increase of the information processing capacity of every single unit. By defining machines as (artificial) actors in the operation subsystem we may interpret this increase of the information processing capacity as a potential improvement of the rational behaviour in the terms of the new institutional economics. The new intuitional economics assume that actors attempt to behave rationally. But because of both limited information retrieval and small respectively restricted information processing capacity, only bounded rational behaviour is possible (Wigand et al. 1997, pp. 34). From this it follows, that (artificial) actors due to the convergence reduces the problems of bounded rationality. If the local intelligence is considered in connection with the parameterization and configuration with the aid of web browsers and/or the better machine monitoring and diagnostics, it is noticeable that the problems of potential principal agent relationships are reduced as well. Principal agent relationships are not fixed fundamentally onto a specific role distribution, but vary in a context-specific way. This means, that an (artificial) actor acts at a particular time as a principal and at another time as an agent. In both cases, the local intelligence has a useful influence. Both the improved search and interpretation of information about partners in interaction processes (screening through the principal), as well as the improved information presentation and transfer (signaling of the agent) reduce the risks in principal agent relationships, e.g. of a moral hazard, and enables pareto-efficient structures of interaction. Simultaneously the shown reduction of the factor specificity and the improvement of the factor mobility lead to a reduction of opportunistic behavior, as well as a decrease of the risk of a hold up. Thus, a situation results in which on the one hand the insecurity and the specificity decrease and on the other hand, the rationality of the actors increases in the whole production system. In a traditional consideration of the new institutional economics, it follows immediately that market coordination forms are optimal for production processes based on the division of labor (Dietl 1993, pp. 155). However, the dichotomous consideration of market and hierarchy is obsolete for more than ten years and is replaced by a differentiation of a large continuum of coordination forms between market and hierarchy (e.g. Williamson 1975, p. 40; Sydow 1992, pp. 103, Wigand et al. 1997, pp. 39). Since we concentrate on company-internal aspects, an externalization of functions is not relevant here as a condition precedent for market coordination forms. We rather assume that in case of the above-discussed modifications of the operation subsystem no externalization occurs and cooperative and/or modular organization principles in hybrid coordination forms are optimal in production processes. This conclusion is supported by the fundamental results of the organization research on modular organizations in general (Wigand et al. 1997, p. 180). However, in contrary to this research, we do not consider the division of existing organizations into modules, but we justify the forming of modules from single (artificial) actors in the operation subsystem. With this understanding of modular structures, modules are no solution of existing institutional and organizational problems, but a consequence of the modifications due to the application of Internet Technologies and Web-based Manufacturing. However, we have to point out that there is a risk that the artificial actors become so-called plastic factors and/or that their plasticity increases. The plasticity of factors denotes the attribute of factors that they require a broad administrative discretion for the production of high-quality results (Schuman 1993, p. 443). Indeed, this administrative discretion is guaranteed by the local intelligence and the shift of property rights to the specific actors. However, it cannot be formalized and is hardly controllable by third parties. Therefore, contracts cannot define the type and extent of the usage of production factors and cannot force an efficient usage (Alchinan/Woodward 1987, pp. 115). The problem is that on the one hand the administrative discretion must be created inevitably, but on the other hand a hold up or a moral hazard may occur (Schuman 1993, p. 443). New institutional economics propose either a contraction at the market or a vertical integration, depending on the importance of the production factor for the quality of the entire product (peripheral vs. central positioning) (Bonus 1987, pp. 87). For the examined case of the internal organization in the transformation process this means for example that peripheral plastic factors are controlled in decentralized 
form, whereas central plastic factors are linked closely to the respective planning authorities, for example to the principal.

The described modifications of the machines and facilities due to the application of Internet Technologies and the Web-based Manufacturing occur fundamentally within the information system as a part of the operation subsystem. For example, the interfaces are reduced between up to now disjunctive subsystems and the compatibility, as well as the interconnectivity with the office systems are increased. For the operation subsystem and information technologies used there follows, transmission time of the information from the shop floor, for example about the machine states, decreases. Due to the homogeneous protocols and standards and the homogeneous network structure in the whole firm, the transparency of both the information system per se and the transformation process related information increase. The transparency is a condition precedent for the reduction of incommensurability, often existing in the business practice between different application contexts, for both the convergent machines and facilities, as well as the information systems per se. Additionally only a description of the relevant contexts and systems is necessary. This is simplified by the application of unified and highly standardized Internet Technologies as well.

Obviously many effects occurring due to the application of Internet Technologies within the machines and facilities also occur within the information system. Particularly the homogeneous networking infrastructure and the compatibility with office systems reduce internal transactions costs and increases factor mobility. Furthermore, Internet Technologies enable a high transparency of the information in the entire production system and of the system per se. Consequently, the insecurity of transactions is reduced so that transaction costs are lowered and a decentralized allocation of property rights becomes possible. Additionally the integration of up to now disjunctive subsystems in the information system, as well as in the entire production system improves the transaction conditions. Due to the rapidly achievable and more extensive information base for decisions in the production system, their substantiation is qualitatively more high grade and much more secure. The modifications lead altogether in the information system to a decreases in the incommensurability of potential contexts of the operation subsystem. Thus, conscious measures, such as typing and standardization, which are often recommended from a transaction costs perspective as a solution for incommensurability induced organizational problems (Picot/Schneider 1988, pp. 111), are not necessary. Actually the application of the Internet Technologies leads to a modification of the quality of the overall system which corresponds to the recommended measures.

The next element of the operation subsystem is the materials flow system. Here we have to emphasize the integration with the machines and facilities, as well as with the information system. In addition to the facilitated physical integration, e.g. by standardized means of transport, unit load conveyor, and cases, the data processing integration is improved. Through the combination with the information system it is possible to determine the state of the materials flow system at any time and from nearly any place. This information can be used in the entire production system in real time and enables fast redesigning of the materials flow itself. The layout of the operation subsystem becomes much more flexible, because the materials flow can be arranged regarding the requirements of the single machines and facilities, without losing efficiency. Thereby the materials flow system becomes a subsystem, which is adaptable to the optimal layout of the operation subsystem. From an institutional perspective the construction of the materials flow can be interpreted as the physical networking of two actors. According to our definition the actors of the operation subsystems are employees, organizational units or (intelligent) machines. In order to generate the materials flow, these actors have to conclude agreements. The objects which are exchanged between the actors can be completely described by the possibilities of the Internet Technologies. This complete description prevents information asymmetries and the often resulting problems, which are discussed in agency theory. Due to the high dynamic environment and changing customer needs, the layout of the operation subsystem and therefore the layout of the materials flow system often changes in industrial practice. Regularly, this implicates new contracts in the operation, respectively the materials flow system. In this case, not only every single sub process is under consideration as an object of the agreement, but also each specific transaction process between two or more actors. Through the available complete information, an acceleration of the contract conclusion is to be expected, which decreases the transaction costs. It follows that changes in the materials flow system are attainable faster and with low-costs. The materials flow system becomes flexible and adaptive. 
The assistance supplied by information technologies for the employees and/or the equipment of work places is a central component of Web-based Manufacturing. The application of Internet Technologies enables multimedia facilities on the shop floor. Together with the aforementioned modification of machines and facilities new human machine interfaces arise. These interfaces allow an intuitive, visual operating of automation technologies. Additionally, due to the internet based networking in the whole firm it is possible to decouple controlling tasks from the automation technologies and to operate the machinery from any place in the firm. The emerging (omnipresent) information availability enables an improvement of the information base of each employee. Due to the higher information availability, the improved information base and the interconnection between working places, an improved decision potential and/or a higher influence sphere of the employees arises.

An institutional perspective has to define the work places and employees as human and organizational actors of the operation subsystem. The comprehensive multimedia abilities and the high information availability decrease agency problems based on information asymmetry. For example, actor's rationality increases due to a reduction of inadequate and/or incomplete information. The broader information base, the solution of interface problems and the standardization of information (technologies) significantly reduce the potential problems within the cooperation between the actors. This enables the already mentioned more rapid transmitting of property rights between the actors, as well as the modification of particular contracts between the actors in the operation subsystem. Human actors are usually not limited in the number of potential contracts, but in production environments a small number of contracts are appropriate. In the operation subsystem these contracts include transfer and allocation of tasks, as well as of the relevant material, authorities to decide and to conclude contracts with other actors. Additionally, the more unspecific the definitions of tasks are the merrier the authorities are in deciding on delivered contracts. In connection with the broader information base of the employees this leads to an inverse information asymmetry. Usually institutional analyses assume an information asymmetry, where the principal or any other controlling actor has more detailed information than the agents. Now we have a situation, where the agents have more information as the principal (Reiss 1998, p. 124). Thus, planning, organization and control of the operation subsystem, respectively the entire production system, also changes.

\subsection{Management Subsystem}

Based on the discussed (technological and organizational) changes in the operation subsystem and their institutional impacts, we can analyze the managerial aspects by evaluating the changes in the management subsystem in order to approach operations management from an institutional point of view. This is legitimate, because a main function of operation management is the (pareto-)efficient configuration of the operation subsystem. This illustrates the proximity of operation management to organizational research, which evaluates alternative organization forms and generates recommendations for efficient organizational structures based on institutional analyses.

Changes in management subsystem may occur because of two aspects: a direct influence of the Internet based Production Concept, e.g. through the recommendation of (new) management instruments, or an indirect influence deriving from changes in the operations system, because the management subsystem has to represent the structure of the operation subsystem. Due to the massive changes in the operation subsystem and the actual existing emphasis of Internet based Production Concepts on the operation subsystem we concentrate on the second aspect. For the analysis of the management subsystem, we examine the task-relevant differences between an operation subsystem without Internet Technologies and an operation subsystem after the introduction of an Internet based Production Concept. Moreover, we use the already introduced differentiation between the system elements as actors and we examine the changes for the specific tasks in the management subsystem. Furthermore, due to the very heterogeneous organizational objects and goals regarding the individual subtasks we divide the influencing parameters in each case. We distinguish on the one hand with the original parameters, which are based on the commitment of the Internet Technologies immediately and correspond to the modifications of the potential elements of the operation subsystem. On the other hand, we distinguish derivative parameters, which are based on business (and organizational) relevance of these modifications. The derivate parameters have to be differentiated into the interpretive characteristics of the actors of an operation subsystem, this mean qualities based on an economic 
interpretation as plasticity, and concrete organization of their relationships from the viewpoint of the new institutional economics, for example due to modifications of the transaction costs.

An important task in operations management is a medium- to short-term capacity management, especially capacity allocation and capacity smoothing. The output of these tasks can be defined as the concrete fulfillment of the qualities and requirements determined in the strategic production management. In detail, tasks are the fine planning, coordination and protection of the medium- to short-term resources of the operation subsystem (capacity dimensioning), the determination of the maintenance politics and measures, as well as the period and process related assignment of the resources (Capacity disposition).

The listing of the subtasks during the capacity allocation and capacity smoothing of resources respectively production factors shows that the original parameters primarily correspond to the modifications of technological system elements. From this it follows that consequences mainly occur for the capacity allocation and capacity smoothing of resources in case of any changes in the quantitative and qualitative availability of these resources or in other words during the selection and (qualitative) evolution of the actors of the operation subsystem. Therefore, we assume that there are no fundamental modifications of original parameters resulting from Internet based Production Concept.

However, the consequences for the derivative parameters are more serious. The modifications of interpretive characteristics determine the capacity allocation and capacity smoothing of the resources in the operation subsystem. An important factor is the factor mobility. In national economics, this describes the spatial, qualificational and sectoral mobility of resources and is an essential condition of an efficient economy structure and/or efficient allocation mechanisms (Schuman 1993, p. 389). In business administration, it approximately corresponds to a highly used variety and/or a high flexibility of the production factors in an operation subsystem. From this it follows that an important consequence of Internet based Production Systems ceteris paribus consists in a variation of the quantitative and qualitative demands for production factors. Such modifications of the capacity allocation and capacity smoothing of production factors due to new technologies and/or production concepts are neither for business administration nor for the business practice new. However, microeconomics and/or institutional economics enable an analysis of the effects, e.g. coordination mechanisms between economic actors, deriving from the modifications. Furthermore, it is possible to evaluate heterogeneous objects as machines and facilities, and employees, as well as organizational units, each interpreted as actors in the operation subsystem. Actually, the increased factor mobility tends to result in a lower demand for production factors. Yet another result is that usability of the factors increase and therefore firms are able to reduce their reserve inventory respectively their organizational slack without reducing flexibility. However, the economical analysis points out the risks and costs of mobility (Schuman 1993, p. 389). They are to be included in the decision-making of capacity allocation and capacity smoothing of production factors, e.g. as additional variables in Production Planning and Control (PPC).

A further interpretive pattern is the plasticity of the production factors. A highly used variety and/or a high flexibility of the actors in the operation subsystem are a necessary, but not sufficient condition for that (Dietl 1995, p. 579). This means, it is to be assumed that an increase of the flexibility and possibly and even an increase of the mobility induce an increase of the plasticity of already existing plastic actors; but it does not cause any generation of plastic actors. For a generation of plastic factors additional to the already existing flexibility high control costs are necessary (Alchinan/Woodward 1987, p. 115). From an institution-economical perspective, this is important since plastic production factors are to be controlled only heavily due to the discretion room needed for high-quality results. Therefore, capacity allocation and capacity smoothing have to aim at reducing the danger of the plasticity and/or at generating measures for reducing and/or the handling of existing plasticity. In case firms could not implement plasticity as criterion in capacity smoothing and coordination they have to choose analog to institution economics between externalization and market coordination mechanism (purchasing of goods and services to be produced). In case the occurrence of plastic production factors is not to be prevented and/or due to strategic considerations, (peripheral) plastic potential factors are not externalized, they have to considered as a restriction in the design of the operation subsystem. In sum, results from the explicit consideration of the plasticity during the capacity allocation and capacity smoothing that a conscious and/or induced increase of the flexibility of production factors does not represent any positive modification of the operation subsystem. With that, we contradict the opinion 
(implicitly) represented in many research projects that flexible production systems are fundamentally positive. Yet, this does not mean that the increasing flexibility causes fundamentally negative consequences. Rather we have to point out that with decisions for the capacity allocation, potential problems of plasticity occurring under specific conditions of Internet Technologies in production processes have to also be considered. Since these problems can compensate the advantages of flexibility, for example in the situation of a hold up or a moral hazard (Alchinan/Woodward 1987, p. 115), the design of the operation subsystem and layout planning have to consider existing plasticity and select the appropriate structures.

The design of the operation subsystem in general and the layout planning in particular constitute the relationships between the actors in the operation subsystem. Since technological and/or process-related innovation fundamentally have an organizational dimension, essential effects of the application of Internet Technologies and the Internet based Production Concepts are to be stated and analyzed with the aid of new institutional economics. Through the modifications found in the analysis of the effects of the Internet based Production Concepts a general expansion of the competences of the actors seems to be useful. Therefore, an appropriate allocation of property rights as a benchmark for competence enlargement is necessary. For this purpose, it must be determined how the hierarchical structures are to be designed in order to keep down transaction costs and reduce problems discussed in agency theory. For example, modularization often occurring from Internet based Production Concepts, increases the complexity of the organization itself. However, the already discussed enhancement of the information processing capacity, as well as the ability, to place a greater number of mutual contracts in the sense of property-rights theory, enable the actors to deal with the high organizational complexity. Thus, additional and until now unknown optimization problems result, e.g. a structural overload (Stolz/Tuerk 1992, p. 853).

However, the consequences of the application of Internet Technologies and Internet based Production Concepts for the design of the operation subsystem can be explained by an analysis of organization theoretic causalities. From an institution economical perspective, the application of Internet Technologies inside and between organizations induces a shift of the optimal organization from hierarchical to cooperative and/or market mechanism. Therefore, essential derivative parameters are the potential cutting of the internal transaction costs due to the improved information flow, a decrease of the insecurity, the improvement of the actors' rationality in the operation subsystem, as well as a (partial) reduction of the information asymmetries. In the examined case of the internal organization, modular structures are to be recommended (Wigand et al. 1997, pp. 34 and pp. 180). These are supported by the combination of the data and process organization to be implemented in Internet based factory structures particularly easily. Furthermore, the increased information processing capacity of actors in the operation subsystem, faster reallocation of property rights due to the reduced transaction costs and information asymmetries, as well as the ability for an efficient conclusion of contracts maintain modular structures in the operation subsystem. From the perspective of the management subsystem, the transfer and the utilization of property rights are considered as an assumption of production order, materials handling, as well as semi-finished or finished goods. From this it results that a decentralized secondary distribution of property rights complies with an enlargement of decentral assignments of employees. However, we have also to emphasize that the production segmentation concept achieves the re-integration of formerly dived processes, in particular of up- and downstream functions in small production units, and the institution economical benefit of modular and/or decentralized structures that are also in production systems. Manufacturing segments are defined as decentralized, product-oriented organizational units in the production, which contain several logistic stages and take on indirect functions, as well as cost responsibility (Wildemann 1987, pp. 36; Corsten/Will 1993, pp. 320). They reduce lead times, delivery times and inventories, as well as increase flexibility. Furthermore, transaction costs are lowered. A further advantage of the manufacturing segments or any other modular respectively decentral organizational approaches in manufacturing is the resulting process orientation leading to a significant reduction of nonconforming goods and waste at the manufacturing level. Our institution economical analysis confirms that it is useful to transmit enlarged decision and action competences to the decentralized units. It is conceivable to allocate inventory management and in-house transportation together with the specific production operations to the decentralized actors in the operation subsystem. The reduction of the up to now prohibitory transaction costs with the aid of Internet Technologies in production processes enables this reallocation of functions. 
The consequences of the factor mobility are more comprehensive. Mobile and therefore variable actors in the operation subsystem are an essential condition of flexibility. Nevertheless, the mobility and/or the variability actors were examined in the previous production research for flexibility only in relatively narrow confines. In institutional economics, the mobility of actors determines a dynamic and very flexible, but although stable operation subsystem. This means, that in an existing operation subsystem within given boundaries for example batch sizes, series specification, customer specification etc. may vary. However, the operation subsystem does not change itself. For example, in the case of workshop production the processing steps between the single tasks are changeable; but the composition of the workshops are unchangeable. In the same way, neither the group composition nor the boundaries of the group change during group manufacturing. However, if companies apply Internet based Production Concepts the communications network and the interaction between actors are in the center of the consideration and have a high influence on operations management. With the aid of the communication network, actors continuously form new (bi- and multilateral) interconnections. The resulting volatile transaction networks formed between the actors in the operation subsystem enable "fluid" structures or even intraorganizational spherical networks (Miles/Snow 1995, pp. 7). Flexibility then means even variability of the operation subsystem in themselves. For example, many actual research projects aim at the development of high flexible infrastructures that enable even the spatial mobility of heavy load facilities (e.g. http://www.mobileproduktion.de).

In case the discussed modifications and the decisions that are necessary for local operations are accomplished with the aid of the local intelligence of the actors, autonomy of the actors arrives. For example, Reinhart (1997) already proposes so-called autonomous production systems in which human and artificial actors act cooperatively and widely independent of central PPC. We understand the presupposed autonomy of artificial actors as the ability of machines or facilities, to execute jobs independently according to presupposed strategies and provided, local goals without direct action of employees. Thus, autonomous production cells have for example a numerically controlled processing unit, as well as the necessary cell-periphery and operate according to presupposed strategies and/or provided, local goals. They execute dispositive and functional tasks autonomously or in cooperation with the responsible human actor in spite of possibly occurring problems and within a determined degree of freedom (Reinhart 1997, p. 250). From the perspective of institution economics the modularization and decentralization of tasks in the production system and the (re)allocation of decision competencies in the operation subsystem is optimal in situations with low transaction costs and a sufficient rationality, as well as a high information processing capacity of the actors.

However, the possibly occurring factor specificity is not based on prohibitory transaction costs and mobility barriers, but on special profits in a concrete application (Schuman 1993, p. 442). The factor specificity or in a more general formulation, the specialization of the actors in the operation subsystem automatically leads to specialization-conditional dependences. These dependences have to be considered during the capacity smoothing in general, as well as during the design of the layout operation subsystem in particular. Such dependences arise in practice for example as process-specific restrictions onto the organization of the operation subsystem. From an institution economical perspective, organizational restrictions may additionally occur to the known technological restrictions. As a solution approach, the institution economical influenced organization research defines dependent and potent resources (e.g. Dietl 1995, pp. 579), respectively in our terminology dependent and potent actors. Dependent actors cooperate with other actors and provide a higher benefit than as is with an autonomous behavior. Actors are potent if other actors of them are dependent. These qualities can occur alone or common.

In case an actor is dependent but not potent, the risks for example of a hold up rise. Therefore, organizational research analyses alternative organization forms concerning their transaction costs efficiency, as well as their suitability regarding dependent and potent, as well as the already discussed plastic actors. The result is, that both from an organizational, as well as from an production-economical point of view a central coordination is always necessary, when due to process-specific and/or specialization-conditional dependences the sum of the local optima (in the subsystems) is lower than the optimum of the super system of the whole production process. However, Dietl (1993) shows that the flexible specialization is a suitable strategy for managing specialization-influenced dependencies and for the increase of the economic adaptability respectively the flexibility as well. For example, an 
expansion of the qualification and/or an increase of the information processing capacity enable a partial decoupling of actors from central planning authorities and increase actors' autonomy.

On the base of the discussed modifications in the operation subsystem and the consequences of the Internet based Production Concepts for the management subsystem discussed until now, conclusions about the optimal production planning and control (PPC) from an institution economical perspective are possible. The PPC aims at the application of mechanisms for economical planning, operation and control of production processes in general. Mechanisms and approaches to the production plan and operation are for example Optimized production Technology (OPT), KANBAN and Manufacturing Resource Planning (MRP II). Main tasks of these concepts are goal-oriented operations' planning and control. Since the operation subsystem is represented for this purpose in the PPC, it follows that modifications of the operation subsystem due to Internet Technologies or Internet based Production Concepts also lead to modifications of the PPC. In other words: The concrete organization of an operation subsystem is important for the design of the production planning and control.

The conditions' precedents for optimal PPC are first of all functioning information processes within the operation subsystem (Kurbel 1999, pp. 53). However, the necessary data quality significantly depends on the data preparation in the operation subsystem. Therefore, the actors in the operation subsystem should be enabled for processing of the information corresponding to PPC locally. The decentralized information processing capacity of the actors postulated in many Internet based Production Concepts allow the required information quality, as well as quantity. However, from an institution economical point of view, the already discussed modifications in the operation subsystem lead to changes in information asymmetries between the planning and operating actors. For example, through the greater transparency of the processes and/or the information about the processes, control costs sink and with that, the transaction costs in the whole production system. In sum, the application of Internet based Production Concepts enables a qualitative, quantitative and chronological optimal information supply for PPC. This means that the coordination costs (ex-ante transaction cost), as well as motivation costs (ex post transaction cost) are lowered (Erlei/Jost 2001, pp. 38).

One further relevant field for the PPC where modifications occur due to Internet based Production Concepts is the organization. We consider not only the single organization processes per se, but also we examine the consequences of Internet based Production Concepts for the PPC. Therefore, we concentrate on the result of the organization process that is the organization as a system of organizational arrangements.

As shown above, essential organizational consequences of Internet based Production Concepts are the tendencies towards the decentralization and modularization in the operation subsystem. These tendencies constitute because of increasing local information processing capacity, as well as the high connectivity of the applied technologies. According to Reiss (1998, p. 117), we assume therefore an enabling of the organization. This means that the organization uses that demanded decentralization potential of the technology for the construction of decentralized structures. From the point of view of the property rights theory, the enabling of the organization combined with the (enlarged) decision rooms cause also a necessity to allocate decision competences and property rights to the decentralized units. A transaction costs perspective shows that Internet based Production Concepts enable the immediate reduction of transaction costs due to the application of information technologies. Furthermore, they enable the generation of potentials for the further reduction of the transaction costs due to the reduction of the transaction frequency and the standardization of the interfaces. For the PPC it follows, that a reallocation of tasks and functions from a (in most cases existent) central unit to the decentralized units is appropriate. Reiss (1998, p. 117) even formulates that without a decentralized PPC 'the autonomy of the decentralized units exists only on the paper'. This situation is intensified by the continuous reorganization of the operation subsystem enabled by the application of Internet based Production Concepts and induces modifications in PPC, e.g. in capacity smoothing.

Positive effects are induced by the implementation of convergent technologies in the operation subsystem. They lead to congruence between system design and organization; enabling a better fit between PPC and organization. The introduction of convergent systems and/or the increase of the local intelligence enable the realization of the concepts of the distributed problem solving as proposed by many Internet based Production Concept, e.g. Web- 
based Manufacturing, and the re-integration of dispositive tasks into the decentralized units. According to Gutenberg (1983, pp. 147), this means particularly the 'planning as a condition of optimal productivity of production processes'. Furthermore, the technologies allow an improvement of the communication of every decentralized unit with the upstream and downstream units because of the integration of information technologies on the shop floor. All actors in the operation subsystem are interconnected so that the continuity of the systems and the availability of information increase. The research on PPC often neglects the optimal use of human resources (Reiss 1998, p. 113). However, the influence of the reduction of coordination processes and the resulting reduction of transaction costs enables the consideration of this criterion in PPC. It takes effect affirmatively that the generation of small manageable structures decreases the problem of the moral hazard in hierarchical operation subsystems from the point of view of agency theory (Wigand et al. 1997, pp. 184).

However, for PPC follows considerable consequences from the application of Internet based Production Concepts. Classical design of (central) systems of PPC assume explicit or implicit, that information asymmetries exists for the benefit of a (central) planner (Reiss 1998, pp. 124). Only this planner has the information necessary for an optimal planning and operation in production processes, whereas employees have the information necessary for the execution of the plans. Agency theory considers the planner principal and the executive units (the actors in the operation subsystem) as agents. An exactly turned around information asymmetries is postulated in this case for the benefit of the agents so that for example the risk of hidden information exists (Elschen 1991, p. 1004). In sum, the effect of Internet based Production Concepts are an improvement of the information structures, the tendency towards the generation of decentralized units and the increase of the local intelligence. According to Reiss (1988), we conclude from these effects that a differentiation between the theoretical knowledge of the PPC, that is only available in a central planning unit, and practical knowledge, that is available in the decentralized units, becomes necessary. Whereas theoretical knowledge "can be explicitly expressed in rules, formulas, and theories", the practical knowledge is the action-oriented knowledge on the shop floor (Nilsson 1998, p. 64). The differentiation between these two types of knowledge in PPC allows in addition to an enabling of the organization by Internet based Production Concepts the empowerment of organization resulting from the (organizational) modifications in the operation subsystem.

Therefore, we can conclude from an institution economical perspective for operations management in Internet based Production Concept that a decentralized system of PPC is needed. This decentralized PPC must assist the decentralized actors in the operation subsystem with the decentralized decision-making, the perception of the autonomy formulated in the Internet based Production Concept and the realization of the production processes. In other words: The organizational and technological modifications caused by Internet based Production Concept in general and Web-based Manufacturing in particular induce a demand for a (partially) decentralized production planning and control.

\section{Conclusion}

In sum, Internet based Production Concepts offer in comparison to the current production concepts many advantages. They apply new technologies widely in order to generate options in production, which were up to now unavailable and in order to realize competitive advantages. However, the application of Internet Technologies leads to modifications in the production system inducing modifications in operations management. A situation emerges, in which planning and control functions are transferred into the operation subsystem, and communication demands between the management subsystem and operation subsystem increase.

If coordination tasks are transferred into the operation subsystem, then additional coordination mechanisms are necessary. Particularly we have to consider an increase in the problem complexity for the actors in the operation subsystem since they take on parts of the management system tasks. In this context, the coordination aims at the optimizing of the relevant subsystem respectively the (cooperative) achievement of superior management goals. But this is problematic because of the complexity of the coordination processes increases with the number of the involved actors. Therefore, it is important to find an appropriate mechanism for the coordination process. We assume that the opportunistic coordination discussed in connection with (technical) multi agent 
systems is an appropriate approach. The opportunistic coordination follows a principle of the maximum freedom degrees in selection problems (principle of opportunism) and a principle of the least commitment (Fox/Kempf 1985, p. 489). Therefore, it enables a direct interaction and communication of the actors in the operation subsystem (Corsten 1999, pp. 319). Yet, commercial PPC systems do not consider the opportunistic coordination.

However, Holstroem/Milgrom (1990, pp. 85) already have shown that immediate contractual relationships between agents (actors) are useful from an institution-economic perspective. Therefore, an institution economical approach to operations management in Internet based Production Concepts must conceptualize the direct communication and the decentralized coordination between actors in the operation subsystem.

\section{References}

1. Alchinan, A. A./Woodward, S. (1987): "Reflections on the Theory of the Firm", in: Journal of Institutional and Theoretical Economics, 143, pp. 110 - 136.

2. Atherton, R. W. (1999): "Moving Java to the Factory", IEEE-Spectrum, 35, 12, pp. 18 - 23.

3. Barua, A./Lee, B. (2001): "The Information Technology Productivity Paradox Revisited: A Theoretical and Empirical Investigation in the Manufacturing Sector", in: Shaw, M. J. (Ed.): Information-Based Manufacturing. Technology, Strategy and Industrial Applications. Kluwer, Boston et al., pp. 37 - 58.

4. Beavers, A. N. (2001): Roadmap to the e-Factory. Auerbach, Boca Raton et al.

5. Black, J. T. (2000): "Manufacturing Systems", in: Swamidass, P. M. (Ed.): Encyclopedia of Production and Manufacturing Management. Kluwer, Boston et al., p. 423 - 431.

6. Blecker, Th. (2001): "Wettbewerbsvorteile durch moderne Produktionskonzepte?", in: Blecker, Th., Gemünden, H. G. (Ed.): Innovatives Produktions- und Technologiemanagement. Festschrift für Bernd Kaluza. Springer Verlag, Berlin et al., pp. 3 - 34.

7. Blecker, Th. (2003a): "Web-based Manufacturing - Ansatz eines betriebswirtschaftlichen Konzepts einer internetbasierten Produktion", Discussion Papers of the University of Klagenfurt No. 2003/01, Klagenfurt 2003.

8. Blecker, Th. (2003b): "Towards an Production Concept based on Internet Technologies", Paper presented at the $6^{\text {th }}$ International Conference on Industrial Engineering and Production Management - IEPM'O3, May 26 - 28, 2003, Porto/ Portugal.

9. Blecker, Th. (2003c): "Entwurf eines auf Internet-Technologien basierenden Produktionskonzepts", in: Wildemann, H. (Ed.): Moderne Produktionskonzepte. TCW-Verlag, Munich.

10. Blecker, Th./Graf, G. (2003): "Internet based Production Concepts - Implications for Business Management", Paper to be presented at the $1^{\text {st }}$ International Conference on Business Economics, Management and Marketing, June 26 - 29, 2003, Athens/Greece.

11. Blecker, Th./Haber, G. (2001): "IP-basierte Geschäftsprozesse in Industrieunternehmen", in: Horster, P. (Ed.): Elektronische Geschäftsprozesse. Grundlagen, Sicherheitsaspekte, Realisierungen, Anwendungen. it - Verlag für Informationstechnik, Höhenkirchen, pp. 338 - 350.

12. Bonus, H. (1987): "Illegitime Transaktionen, Abhängigkeit und institutioneller Schutz", in: Hamburger Jahrbuch für Wirtschafts- und Gesellschaftspolitik, 32, pp. 87 - 107

13. Cheng, K./Pan, P. Y./Harrison, D. K. (2001): "Web-based design and manufacturing support systems: implementation perspectives", International Journal of Computer Integrated Manufacturing, 14, 1, pp. $14-27$.

14. Corsten, H. (1999): "Anwendung der opportunistischen Koordinierung in dezentralen PPS-Systemen. Ein Ansatz auf Basis von Multiagentensystemen", in: Nagel, K./Erben, R. F./Piller, F. T. (Ed.): Produktionswirtschaft 2000. Perspektiven für die Fabrik der Zukunft. Gabler Verlag, Wiesbaden, pp. $319-347$.

15. Corsten, H./Will, T. (1993): Reflections on Competitive Strategy and its Impact on Modern Production Concepts. In: management international review, 33, 4, pp. 315 - 334.

16. Dietl, H. (1993): Institutionen und Zeit, Mohr, Tuebingen.

17. Dietl, H. (1995): "Institutionelle Koordination spezialisierungsbedingter Abhängigkeiten", in: Zeitschrift für Betriebswirtschaft, 65, 6, pp. 569 - 585. 
18. Elschen, R. (1991): "Gegenstand und Anwendungsmöglichkeiten der Agency-Theorie", in: Schmalenbachs Zeitschrift für betriebswirtschaftliche Forschung, 43, 11, pp. 1002 - 1012

19. Erlei, M./Jost, P.-J. (2001): "Theoretische Grundlagen des Transaktionskostenansatzes", in: Jost, P.-J. (Ed.): Die Prinzipal-Agenten-Theorie in der Betriebswirtschaftslehre, Schaeffer-Poeschel, Stuttgart, pp. $35-75$

20. Fandel, G./Lorth, M. (2001): "Produktion und Logistik", in: Jost, P.-J. (Ed.): Die Prinzipal-AgentenTheorie in der Betriebswirtschaftslehre, Schaeffer-Poeschel, Stuttgart, pp. 273 -329.

21. Fels, G. (1992): "Privateigentum und Marktwirtschaft", in: Zeitschrift für Betriebswirtschaft, 62, 10, pp. $1043-1053$.

22. Foss, K. (1998): Technological interdependencies, specialization and coordination: a property rights perspective on the nature of the firm. Danish Research Unit for Industrial Dynamics (DRUID) Working Paper No. 98-10, Aalborg.

23. Fox, B.R./Kempf, K. G. (1985): "Complexity, Uncertainty and Opportunistic Scheduling", in: Weisbin, C. R. (Ed.): Proceedings of the Second Conference on Artificial Intelligence Applications. The Engineering of Knowledge-Based-Systems, Fontainebleau, 11.-13.12.1985, Washington 1985, pp. 487 - 492.

24. Franck, E./Jungwirth, C. (2001): "Produktion", in: Jost, P.-J. (Ed.): Der Transaktionskostenansatz in der Betriebswirtschaftslehre, Schaeffer-Poeschel, Stuttgart, pp. $273-299$.

25. Furubotn, E. G./Richter, R. (1991, Ed.): The new institutional economics: a collection of articles from the Journal of Institutional and Theoretical Economics. Mohr, Tuebingen.

26. Gutenberg, E. (1983): Grundlagen der Betriebswirtschaftslehre. Erster Band: Die Produktion, $24^{\text {th }}$ Ed. Springer Verlag, Berlin et al.

27. Holmström, B./Milgrom, P. (1990): "Assigning Tasks to Agents", in: Journal of Institutional and Theoretical Economics, 146, pp. 85 - 105.

28. Huang, G. Q./Mak, K. L. (2001a): "Web-integrated manufacturing: recent developments and emerging issues", in: International Journal of Computer Integrated Manufacturing, 14, 1, pp. 3 - 13.

29. Huang, G. Q./Mak, K. L. (2001b): "Issues in the development and implementation of web applications for product design and manufacture", International Journal of Computer Integrated Manufacturing, 14, 1, pp. $125-135$.

30. Huang, G. Q./Mak, K. L. (2003): Internet Applications in Product Design and Manufacturing. Springer Verlag, Berlin et al.

31. Kuehnle, H./Klostermeyer, A./Lorentz, K. (2001): "A Paradigm Shift to Distributed Systems in Plant Automation", in: Fares Sebaaly, M. (Ed.): The International NAISO Congress on Information Science Innovations ISI' 2001 (Dubai, $17^{\text {th }}-21^{\text {st }}$ March) - Proceedings, pp. $463-469$.

32. Kurbel, K. (1999): Produktionsplanung und-steuerung. Oldenbourg, München - Wien.

33. Miles, R. E./Snow, C. C. (1995): "The New Network Firm: A Spherical Structure Built on a Human Investment Philosophy", in: Organizational Dynamics, 24, pp. 5 - 18.

34. Naylor, J. (2002): Introduction to Operations Management. $2^{\text {nd }}$ Edition, Pearson Education, Harlow, England et al.

35. Neumann, G. (2002): "Neue Medien und deren Einfluss auf die Betriebswirtschaft", FAZ - Frankfurter Allgemeine Zeitung, February 25 2002, p. 26.

36. Nilsson, J. (1998): "Handling the unexpected - a case study of computer support for workplace learning in chemical industry", in: Smeds, R./Riis, J. O. (Ed.): Experimental Learning in Production Management. IFIP TC5/WG5.7 Third Workshop on Games in Production Management: The effects of using simulation games in universities and industry, 27-29 June, Espoo, Finland. Chapman \& Hall, London et al., pp. 60 - 73.

37. $\quad$ North, D. C. (1991): "Institutions", in: Journal of Economic Perspectives, 5, pp. 97 - 112.

38. Pabadis (2001): The PABADIS Approach. Pabadis White Paper, URL: http://www.pabadis.org/downloads/pabadis_white_paper.pdf.

39. Picot, A./Schneider, D. (1988): "Unternehmerisches Innovationsverhalten, Verfügungsrechte und Transaktionskosten", in: Budäus, D./Gerum, E./Zimmermann, G. (Ed.): Betriebswirtschaftslehre und Theorie der Verfügungsrechte, Gabler Verlag, Wiesbaden, pp. $91-118$.

40. Rehg, J. A./Kraebber, H. W. (2001): Computer-Integrated Manufacturing. ${ }^{\text {nd }}$ Edition, Prentice Hall, Upper Saddle River, New Jersey - Columbus, Ohio. 
41. Reinhart, G. (1997): "Autonome Produktionssysteme", in: Schuh, G./Wiendahl, H.P. (Ed.): Komplexität und Agilität - Steckt die Produktion in der Sackgasse? Springer Verlag, Berlin et al., pp. 244 - 255.

42. Reiss, M. (1998): "Organisatorische Entwicklungen", in: Corsten. H./Gössinger, R. (Ed.): Dezentrale Produktionsplanung und -steuerungs-Systeme. Eine Einführung in 10 Lektionen, Kohlhammer, Stuttgart Berlin, pp. 109 - 141.

43. Schüber, E. (2001): "Die Internet-Fabrik". in: Praxis der Wirtschaftsinformatik, 219, pp. 7 - 15.

44. Schumann, J. (1993): Grundzüge der mikroökonomischen Theorie. $6^{\text {th }}$ Ed., Springer Verlag, Berlin et al.

45. Shaw, M. J. (2001): "Information-Based Manufacturing with the Web", in: Shaw, M. J. (Ed.): InformationBased Manufacturing. Technology, Strategy and Industrial Applications. Kluver, Boston et al., pp. 7 - 21.

46. Siemens AG (1999): SIMATIC NET. Industrial Ethernet, White Paper.

47. Slack, N./Lewis, M. (2002): Operations Strategy. Pearson Education, Harlow, England et al.

48. Stolz, H. J. / Türk, K. (1992): "Individuum und Organisation", in: Frese, E. (Ed.): Handwoerterbuch der Organisation, Schaeffer-Poeschel, Stuttgart, pp. 841 - 855.

49. Sydow, J. (1992): Strategische Netzwerke. Evolution und Organisation, Gabler Verlag, Wiesbaden.

50. Veeramani, D./Wang, K. (2001): "Performance Analysis of Auction-Based Distributed Shop-Floor Control Schemes from the Perspective of the Communication System", in: Shaw, M. J. (Ed.): Information-Based Manufacturing. Technology, Strategy and Industrial Applications, Kluver, Boston et al., S. $243-266$.

51. Waller, D. L. (1999): Operations Management. A Supply Chain Approach. International Thomson Business Press, London et al.

52. Walras, L. (1874): Éléments d'économie politique pure ou théorie de la richesse social, Paris. Englisch: Elements of pure economics or the theory of social wealth, London 1954.

53. Wigand, R./Picot, A./Reichwald, R. (1997): Information, Organization and Management. Expanding Markets and Corporate Boundaries. John Wiley \& Sons, Chichester et al.

54. Wildemann, H. (1987): "Fertigungssegmentierung", in: Zeitschrift des Vereins Deutscher Ingenieure für Maschinenbau und Metallbearbeitung, 129, 11, pp. 36 - 43.

55. Wildemann, H. (2000): "Kernkompetenz-Management: Mit intelligenten Technologien Kunden binden", in: Wildemann, H. (Ed.): Kernkompetenzen und E-Technologien. TCW-Verlag, Munich, pp. 15 - 59.

56. Williamson, O. E. (1975): Markets and Hierarchies: Analysis and Antitrust Implications. A Study in the Economics of Internal Organization, Free Press, London. 
Notes 